\title{
Outline of vertical displacement of the 2004 and 2005 Sumatra earthquakes revealed by satellite radar imagery
}

\author{
Mikio Tobita, Hisashi Suito, Tetsuro Imakiire, Min Kato, Satoshi Fujiwara, and Makoto Murakami \\ Geographical Survey Institute, Tsukuba, Ibaraki 305-0811, Japan
}

(Received October 3, 2005; Revised December 3, 2005; Accepted December 13, 2005)

\begin{abstract}
Analyses of satellite radar imagery before and after the 2004 and 2005 Sumatra earthquakes reveal an overview of the uplift and submergence pattern of islands along the subduction zone and provide an outline of the regions that experienced coseismic vertical deformation. We find evidence of crustal deformation from the northern tip of the Andaman Islands to Nias Island. A line $145 \mathrm{~km}$ east of the trench separates western uplifted zone from eastern subsided zone. Agreement with the field observation demonstrates the feasibility of our method. We find that radar imagery analysis is more efficient for investigating vertical displacements than similar techniques using optical sensors.
\end{abstract}

Key words: Sumatra, SAR, satellite, emergence, subsidence, tsunami.

\section{Introduction}

Analyses of seismic waves (e.g., Ishii et al., 2005; Krüger and Ohrnberger, 2005; Ni et al., 2005) suggested that the 2004 Sumatra earthquake ruptured over a distance of 1,000 $\mathrm{km}$. A map of uplift and subsidence may provide further constraints on the extent of the rupture.

Field observations using GPS (Vigny et al., 2005; Banerjee et al., 2005) and of a coral microatoll (e.g., Sieh et al., 1999; Zachariasen et al., 2000) provide information on deformation at some sites. These in-situ observations, however, cannot cover the entire area, because it is difficult to enter some regions, because of the existence of military bases, aboriginal and armed groups, and the collapse of bridges due to tsunami. Remote sensing could be a method of obtaining the whole image of the crustal deformation along the rupture zones.

We use satellite Synthetic Aperture Radar (SAR) images to detect shoreline changes and map areas of seismic uplift and subsidence. In addition to improving our understanding of the geometry of the plate interface and of the deformation associated with the earthquake, this map can constrain the spatial extent and direction of fault slip, because the line of no vertical changes is close to the down-dip edge of the seismic fault.

\section{Extraction of Shoreline Changes and Tsunami Inundated Areas from SAR Images}

We processed raw SAR data and generated intensity images of microwave backscatter intensity from the surface, where the image intensity depends on the roughness of the surface. We coregister two SAR intensity images acquired before and after the earthquake using tie points and then

Copy right(c) The Society of Geomagnetism and Earth, Planetary and Space Sciences (SGEPSS); The Seismological Society of Japan; The Volcanological Society of Japan; The Geodetic Society of Japan; The Japanese Society for Planetary Sciences; TERRAPUB geocode the pair. In order to automatically determine regions of backscatter changes, we combine the pair of images to form a single image. We first assign intensity variations in the pre-earthquake image to variations in red $((\mathrm{R}$, $\mathrm{G}, \mathrm{B})=(100 \%, 0 \%, 0 \%))$, and variations in the postearthquake image to cyan $((\mathrm{R}, \mathrm{G}, \mathrm{B})=(0 \%, 100 \%, 100 \%))$.

The additive process between red and cyan results in the gray, red and cyan respectively, at areas that are unchanged, areas where backscatter decreased, and areas where backscatter increased.

Figure 1 shows an example of the color additive process at Cape Sudhen in NW Sumatra. An area colored red in the right image is a region where the reflection (backscatter) intensity is decreased due to submergence and tsunami inundation.

We processed about 60 scenes of SAR data to investigate coastal changes in most of the islands along the possible rupture zones, and Table 1 summarizes the SAR data, the results of which are shown in Figs. 3 and 4.

\section{Results: Coastal Changes along the Subduction Zone}

Here we present the results of the analyses described in Section 2. Figure 2 shows the investigated region and areas from which the results in Figs. 3 and 4 were obtained.

3.1 Emergence and submergence due to 2004 Indian Ocean earthquake

Cyan in the SAR images of Figs. 3(a), (b), (c), (d), and (e) represents emergence in Interview, North Sentinel, South Sentinel, Simeulue and Little Andaman Islands, respectively. The emergence was caused by uplift due to the 26 December 2004 Sumatra earthquake.

Red in Figs. 3(f) and (g) shows submergence in Great Nicobar Island and northwestern Sumatra. The area in light red on the west coast of northwestern Sumatra in Fig. 3(g), where the reflective intensity is slightly decreased, is an area of tsunami inundation. The submergence is due to 
Table 1. Satellite SAR Data and Tide Level.

\begin{tabular}{llcccccc}
\hline Figure & Island & $\begin{array}{c}\text { Data acquisition } \\
\text { date (UTC) }\end{array}$ & Satellite & Orbit & $\begin{array}{c}\text { Incidence } \\
\text { angle (deg) }\end{array}$ & $\begin{array}{c}\text { Polarization } \\
\begin{array}{c}\text { Tide } \\
\text { level (cm) }\end{array}\end{array}$ \\
\hline 3(a) & Interview & 4-Oct-03/2-Jan-05 & RADARSAT-1 & Descending & 44 & $\mathrm{HH} / \mathrm{HH}$ & $+45 /-28$ \\
3(b) & N. Sentinel & 4-Oct-03/2-Jan-05 & RADARSAT-1 & Descending & 44 & $\mathrm{HH} / \mathrm{HH}$ & $+38 /-25$ \\
3(c) & S. Sentinel & 4-Oct-03/2-Jan-05 & RADARSAT-1 & Descending & 44 & $\mathrm{HH} / \mathrm{HH}$ & $+36 /-24$ \\
3(d) & Simeulue & 22-Jul-03/17-Feb-05 & RADARSAT-1 & Ascending & 47 & $\mathrm{HH} / \mathrm{HH}$ & $-15 /-2$ \\
3(e) & L. Andaman & 4-Oct-03/2-Jan-05 & RADARSAT-1 & Descending & 44 & $\mathrm{HH} / \mathrm{HH}$ & $+35 /-23$ \\
3(f) & G. Nicobar & 27-Dec-92/12-Jan-05 & ERS-1/ERS-2 & Descending & 23 & $\mathrm{VV/VV}$ & $+24 /+32$ \\
3(g) & NW Sumatra & 22-Jul-03/17-Feb-05 & RADARSAT-1 & Ascending & 47 & $\mathrm{HH} / \mathrm{HH}$ & $-11 /+2$ \\
4(a) & Nias & 4-Feb-05/15-Apr-05 & ENVISAT & Ascending & 42 & $\mathrm{VV/VV}$ & $-10 /-4$ \\
4(b) & Bangkaru & 4-Feb-05/15-Apr-05 & ENVISAT & Ascending & 42 & $\mathrm{VV/VV}$ & $-10 /-5$ \\
4(c) & Tuangku & 4-Feb-05/15-Apr-05 & ENVISAT & Ascending & 42 & $\mathrm{VV/VV}$ & $-10 /-5$ \\
\hline
\end{tabular}

The two polarizations and two tide levels correspond to the two acquisition dates.
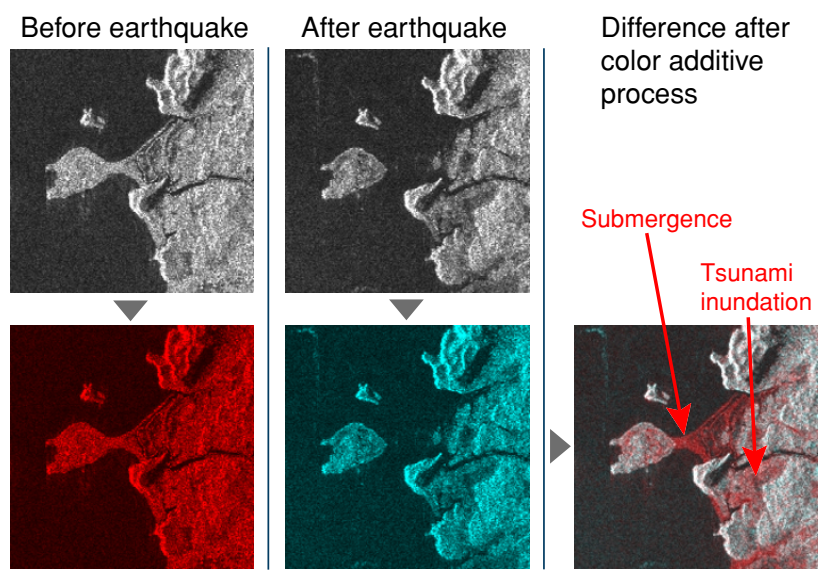

Fig. 1. An example of color additive process of image of NW Sumatra. Red and light red areas represent areas of submergence and tsunami inundation.

subsidence caused by deformation and coastal erosion by the tsunami.

3.2 Uplift and subsidence caused by 2005 earthquake

Figure 4 shows uplift and subsidence caused by the 28 March 2005 earthquake. At the northwestern coast of Nias Island, new land emerged over a distance of about $1 \mathrm{~km}$. More than 10 new islands were created, with diameters from $100 \mathrm{~m}$ to $1.5 \mathrm{~km}$. The whole of Bangkaru Island was uplifted. The coast of Tuangku Island submerged along a distance of $100 \mathrm{~m}$ at maximum. The line of no vertical change (the pivot line) separating the uplift and subsidence zones is shown in orange.

A compilation of uplifted and subsided coastal regions revealed by our SAR image analyses are depicted in cyan and red in Fig. 5, respectively.

\section{Discussion}

A line $145 \mathrm{~km}$ east of the trench separates western uplifted zone from eastern subsided zone as shown in Fig. 5. A line of no vertical changes is near the down-dip edge of the seismic fault in this area. It is inferred that the depth of the seismic coupling is uniform along this subduction zone.

To check the validity of our method, we compared our

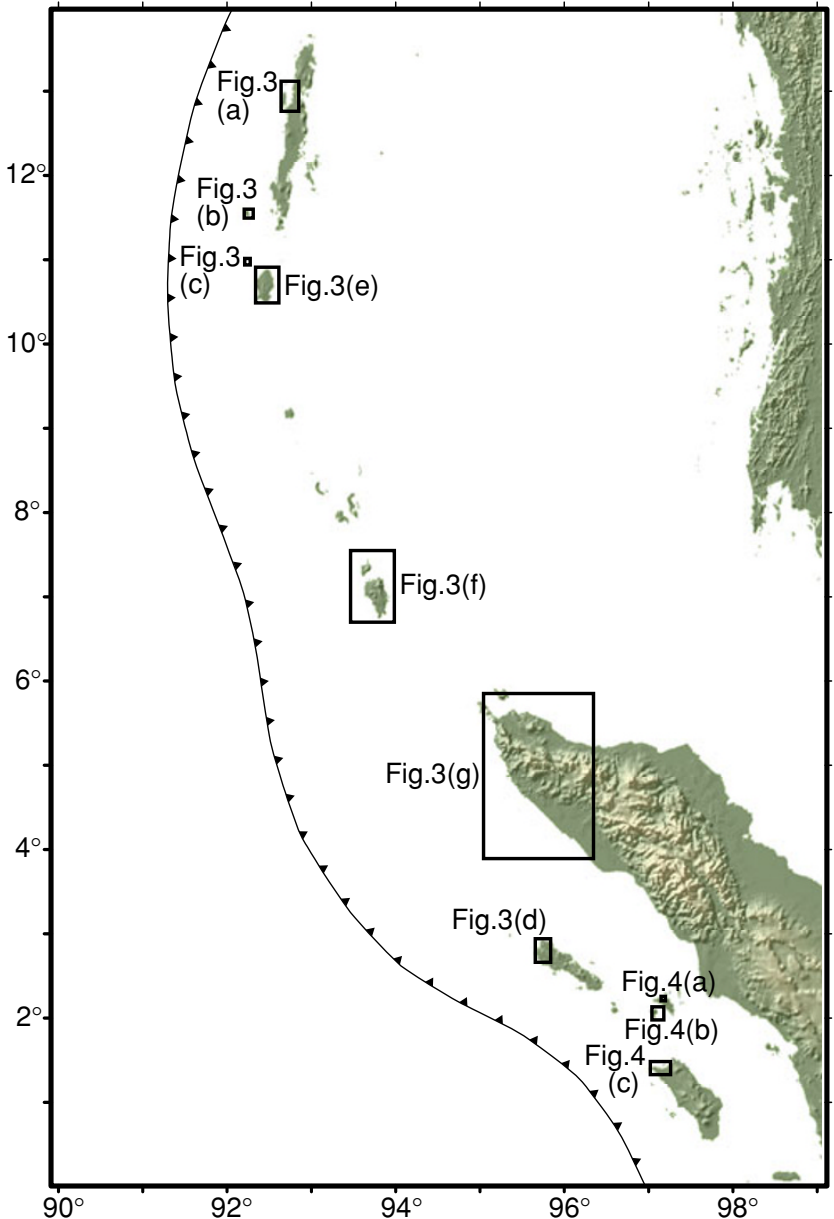

Fig. 2. The investigated region and areas from which the results in Figs. 3 and 4 were obtained.

result with the results of the field survey by Tectonics Observatory, California Institute of Technology (Meltzner et al., 2006). The cyan ribbons in the image of Simeulue in Fig. 3(d) correspond well with their results. Generally, a wider ribbon corresponds to greater uplift.

The major error source of our method is tide level difference between two acquisition time. The emerged area of Interview Island in Fig. 3(a), for example, may be exag- 

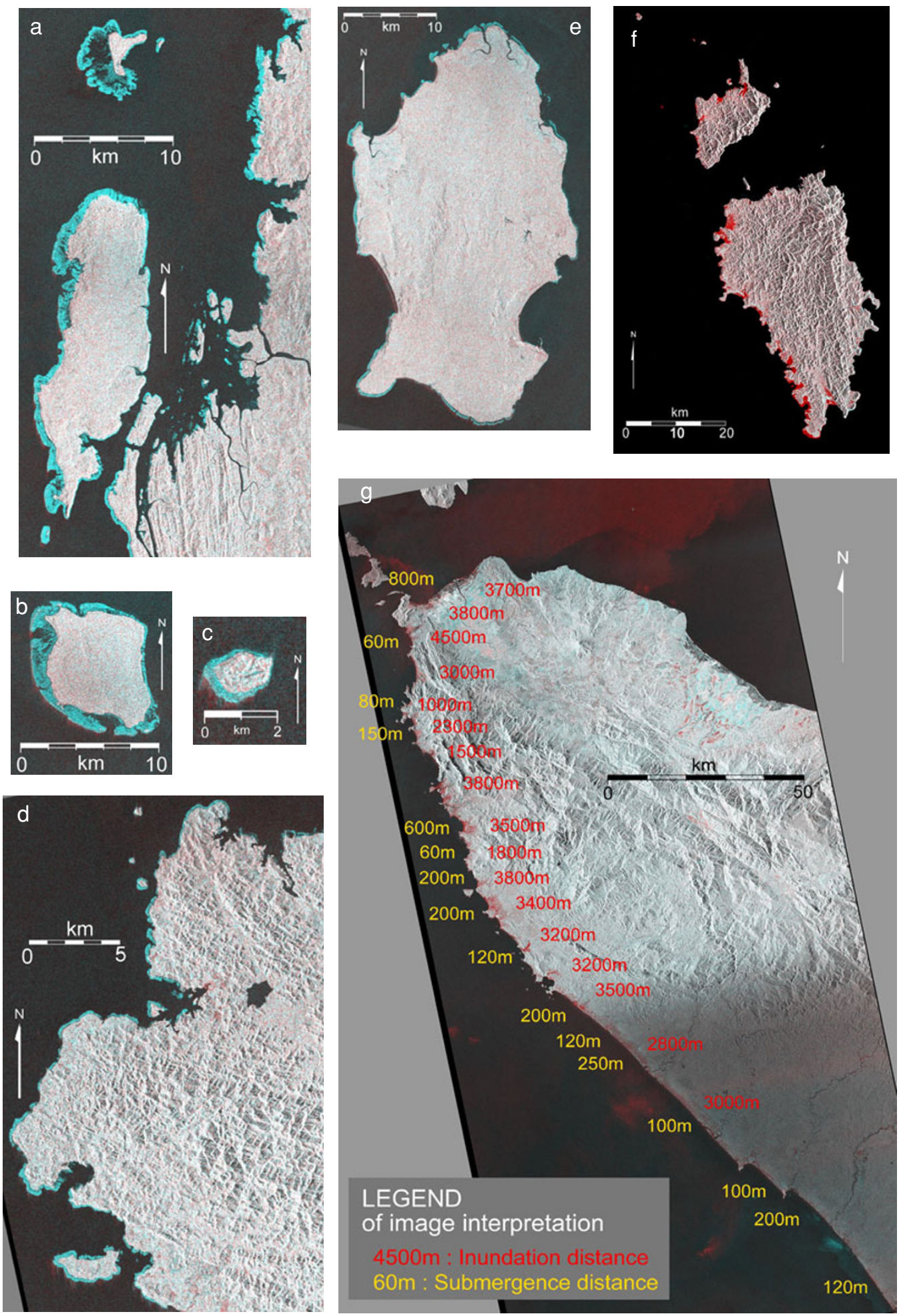

Fig. 3. Examples of coastal changes caused by the 2004 earthquake derived from SAR data. (a) Interview Island, (b) North Sentinel Island, (c) South Sentinel Island, (d) Simeulue Island, (e) Little Andaman Island, (f) Great Nicobar Island, (g) NW Sumatra.

gerated bacause of $47 \mathrm{~cm}$ (Table 1) of tide level difference. In contrast to that, there are only $5-6 \mathrm{~cm}$ tide level differences, and coastal change detection at Tuangku, Bangkaru and Nias Islands in Figs. 4(a), (b) and (c) has small error by the tide differences. The pivot line in Fig. 4(d) is agreed well with the field survey by R. Briggs et al. (Personal communication, 2005). Therefore, our method will not have a big error except the tide level difference.
Although our method cannot yield quantitative values of vertical displacement, it is suitable for mapping widely distributed uplifted and submerged areas. We found that our method of using SAR data was more efficient for investigating vertical displacements than image comparison using optical satellite sensor data. Compared to the optical images, SAR images have the following three benefits. (1) Microwaves penetrate clouds which obstruct the optical view 


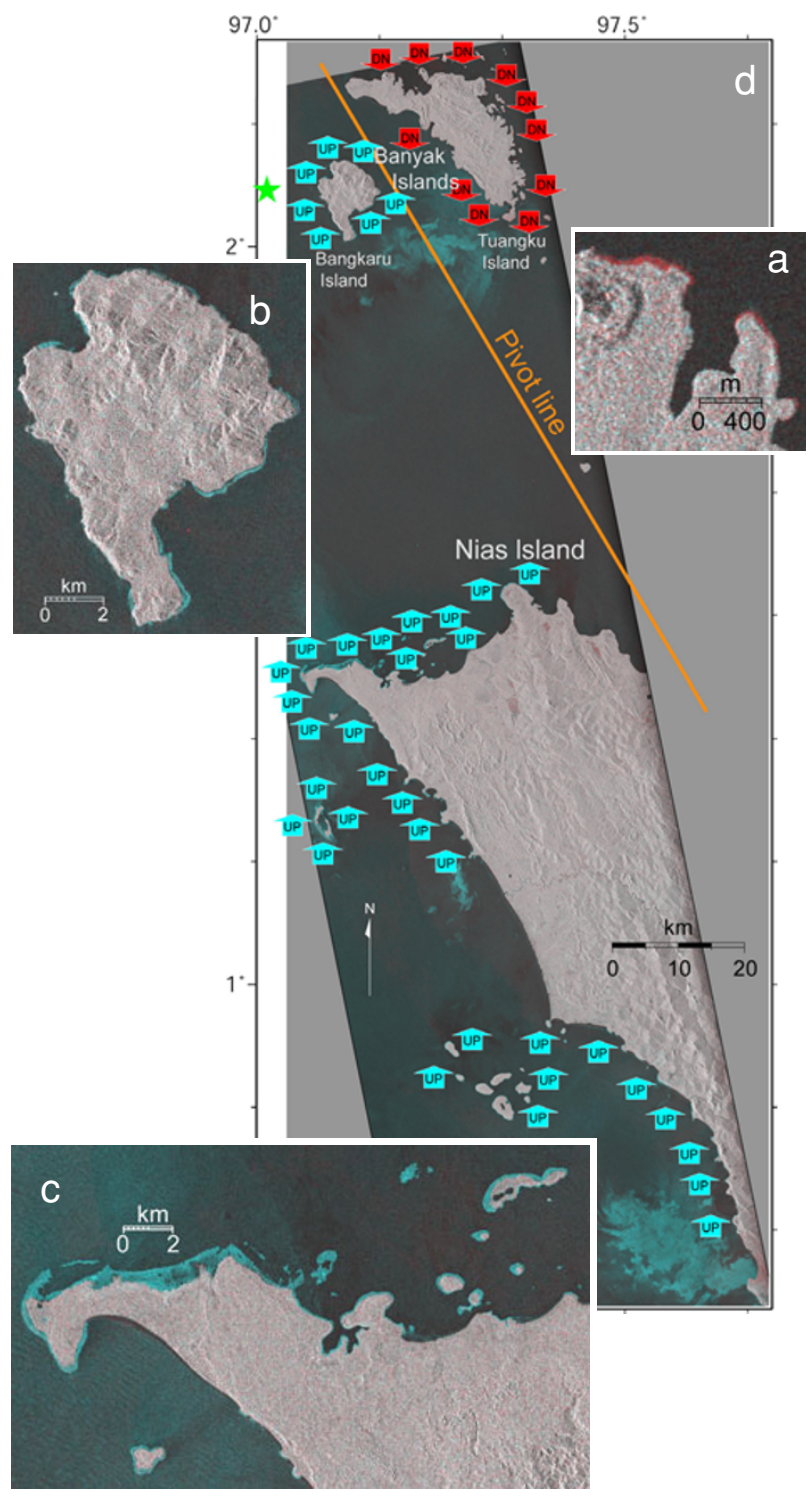

Fig. 4. Shoreline changes caused by the 2005 earthquake, derived from ENVISAT SAR data. (a) Tuangku Island, (b) Bangkaru Island, (c) Nias Island, and (d) overview.

and whose shadows make comparisons difficult. The probability of the existence of archived SAR image data before seismic events of a target area is much higher, particularly in the tropical regions because extensive cloud cover precludes the acquisition of optical data. (2) Data acquisition request of a post-event image for SAR interferometry analysis enables us to obtain an image with the same look angle, which is suitable for correction-free change detection, because the SAR interferometry requires a small distance between satellites. (3) Active radar signals provide stable image intensity, which is suitable for precise comparison and automatic change detection.

Acknowledgments. We are grateful to M. Kaidzu, M. Tsuzawa, and Y. Kumaki for their assistance. We thank Fumi Hayashi for her help. ENVISAT ASAR raw data copyright ESA. RADARSAT raw data copyright CSA.

\section{References}

Banerjee, P., F. F. Pollitz, and R. Bürgmann, The size and duration of the

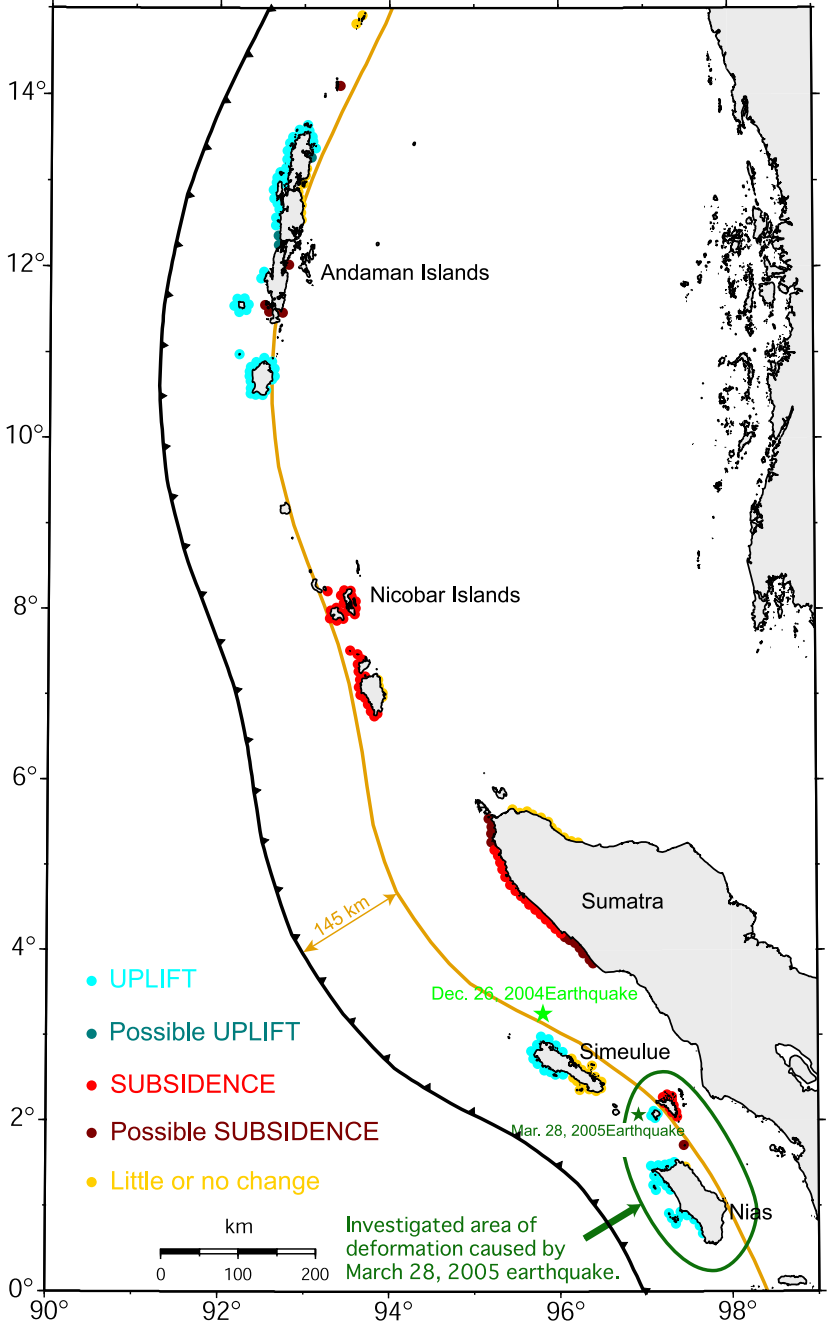

Fig. 5. Uplift and subsidence caused by the 2004 and 2005 (in the green oval) Sumatra earthquakes extracted from satellite SAR images. The orange line $145 \mathrm{~km}$ east of the trench was drawn using GIS.

Sumatra-Andaman earthquake from far-field static offsets, Science, $\mathbf{3 0 8}$, 1769-1772, 2005.

Ishii, M., P. M. Shearer, H. Houston, and J. E. Vidale, Extent, duration and speed of the 2004 Sumatra-Andaman earthquake imaged by the Hi-Net array, Nature, 435, 933-936, doi:10.1038/nature03675, 2005.

Krüger, F. and M. Ohrnberger, Tracking the rupture of the $\mathrm{Mw}=9.3$ Sumatra earthquake over $1,150 \mathrm{~km}$ at teleseismic distance, Nature, 435, 937939, doi:10.1038/nature03696, 2005.

Meltzner, A. J., K. Sieh, M. Abrams, D. C. Agnew, K. W. Hudnut, J. P. Avouac, and D. H. Natawidjaja, Uplift and Subsidence Associated with the Great Aceh-Andaman Earthquake of 2004, J. Geophys. Res., doi:10. 1029/2005JB003891, 2006.

Ni, S., H. Kanamori, and D. Helmberger, Energy radiation from the Sumatra earthquake, Nature, 434, 582, 2005.

Sieh, K., S. N. Ward, D. Natawidjaja, and B. W. Suwargadi, Crustal deformation at the Sumatran subduction zone revealed by coral rings, Geophys. Res. Lett., 26, 3141-3144, 1999.

Vigny, C., W. J. Simons, S. Abu, R. Bamphenyu, C. Satirapod, N. Choosakul, C. Subarya, A. Socquet, K. Omar, H. Z. Abidin, and B. A. Ambrosius, Insight into the 2004 Sumatra-Andaman earthquake from GPS measurements in southeast Asia, Nature, 436, 201-206, 2005.

Zachariasen, J., K. Sieh, F. W. Taylor, and W. S. Hantoro, Modern vertical deformation above the Sumatran subduction zone: paleogeodetic insights from coral microatolls, Bull. Seism. Soc. Am., 90, 897-913, 2000.

M. Tobita (e-mail: tobita@gsi.go.jp), H. Suito, T. Imakiire, M. Kato, S. Fujiwara, and M. Murakami 